\title{
PENGARUH GAYA HIDUP DAN LITERASI KEUANGAN TERHADAP PENGELOLAAN KEUANGAN MAHASISWA DI KOTA MAKASSAR
}

\author{
Fuji Sucihati \\ Institut Bisnis dan Keuangan Nitro \\ Fujisucihati94@gmail.com
}

\begin{abstract}
Abstrak
Tujuan utama dari penelitian ini yaitu dapat menganalisis dampak gaya hidup dan literasi keuangan pada manajemen keuangan. Metode yang digunakan pada penelitian ini adalah penelitian kuantitatif. Populasi penelitian ini adalah mahasiswa di Kota Makassar dengan teknik sampling aksidental menggunakan 100 sampel. Teknik analisis menggunakan regresi berganda, uji-t, dan uji F. Hasil uji-t menunjukkan bahwa gaya hidup dan literasi keuangan berpengaruh secara parsial terhadap manajemen keuangan. Dan hasil uji $F$ menunjukkan bahwa gaya hidup dan literasi keuangan secara simultan mempengaruhi manajemen keuangan.
\end{abstract}

Kata kunci: gaya hidup, literasi keuangan, pengelolaan keuangan

\section{Pendahuluan}

Dengan perkembangan zaman, gaya hidup terus berkembang dan berubah, Era globalisasi telah membawa dampak yang sangat besar bagi kehidupan masyarakat, membawa perubahan positif dan negatif. Teknologi berkembang sangat pesat, salah satunya adalah teknologi informasi. Cara hidup mahasiswa telah merambah ke semua kalangan termasuk mahasiswa, tidak dapat dipungkiri bahwa gaya hidup mahasiswa saat ini sangat berbeda dengan gaya hidup mahasiswa masa lalu. Jika dulu mahasiswa sering menghabiskan 
waktu dengan membaca buku, sekarang mahasiswa sering menghabiskan waktu di mall dan sebagainya untuk mencari kesenangan.

Banyak kehidupan siswa yang berlawanan dengan situasi keuangan keluarga mereka, tetapi mereka memaksa diri mereka sendiri untuk sebanding dengan orang lain di sekitar mereka, yang mungkin kaya secara finansial. Hal ini dikarenakan reputasinya yang membuat mereka selalu mencari informasi tentang gaya hidup terkini dan perilaku konsumen agar tidak dilupakan, sehingga tanpa disadari mereka meninggalkan tanggung jawab orang tuanya, yaitu harus menggunakan dana yang dialokasikan untuk memenuhi kebutuhannya. terkadang mengarah pada fakta bahwa dana tidak sepenuhnya digunakan bahkan sebelum pengiriman berikutnya, yang membuat kesenangan yang tidak berguna menjadi tidak berguna.

Salah satu faktor yang memengaruhi manajemen pengelolaan keuangan mahasiswa adalah literasi keuangan (Arijanto, 2010 dalam Sina dan Noya, 2012 dan Hardiayanti 2016). Mahasiswa yang memiliki literasi keuangan yang tinggi akan mampu bersikap dan berperilaku positif dalam setiap keputusan yang diambil. Memang tidak banyak penelitian yang menjelaskan bahwa literasi keuangan dapat memberi pengaruh terhadap pengelolaan keuangan. Namun, jika dipahami dengan cermat dan teliti, literasi keuangan akan membawa dampak baik bagi diri seseorang karena akan menimbulkan sikap positif dalam diri seperti tanggung jawab, kemandirian, kejujuran, dan optimalisasi kebebasan dalam pengelolaan keuangan (Chotimah dan Rohayati, 2015). Selain literasi keuangan, gaya hidup hedonisme juga mempengaruhi manajemen keuangan pribadi. Adanya kebiasaan hangout bersama teman-teman untuk sekedar berkumpul atau jalan-jalan, kegiatan kuliner, nonton, dan lain sebagainya tanpa disadari hal tersebut menjadi kebiasaan buruk dan menjadi salah satu faktor membengkaknya pengeluaran uang bulanan mahasiswa (Chotimah dan Rohayati, 2015).

Pengetahuan keuangan yang baik secara subjektif dan objektif berpengaruh terhadap perilaku keuangan secara signfikan dan pengetahuan keuangan merupakan prediktor utama dalam membentuk perilaku keuangan 
(Universitas Pendidikan Undikhsha,2015:67). Kemampuan seseorang dalam melakukan perencanaan, pengelolaan serta pengendalian keuangan erat kaitannya dengan pengetahuan seseorang tersebut terhadap konsep literasi keuangan.

\section{Kajian Pustaka dan Model Metode Penelitian}

Gaya Hidup

Menurut Sugihartati $(2010$ : 159) gaya hidup adalah cara hidup mencakup sekumpulan kebiasaan, pandangan dan pola-pola respon terhadap hidup, serta terutama perlengkapan untuk hidup. Gaya hidup juga merupakan cara bagaimana seseorang hidup, termasuk bagaimana seseorang menggunakan uangnya, bagaimana ia mengalokasikan waktunya dan sebagainya (Kanserina, $2015: 3)$.

Gaya hidup (life style) yang ditampilkan antara kelas sosial masyarakat dengan kelas sosial yang lain berbeda dalam banyak hal, dan bahkan setiap kelas memiliki upaya untuk mengembangkan cara hidup yang unik. Berbeda dengan kelas sosial yang lebih rendah mereka biasanya konservatif di bidang agama, moralitas, dan pakaian. Makanan, cara baru perawatan kesehatan, cara mendidik anak, dan hal lainnya Selain itu, gaya hidup dan penampilan kelas menengah ke atas biasanya lebih banyak pesona dan eksklusif.

Seorang yang cenderung berpenghasilan besar akan dengan mudah mengalokasikan uangnya untuk kesenangan dan kemewahan tanpa memikirkan nominal. Gaya hidup secara luas diidentifikasikan sebagai cara hidup yang diidentifikasikan oleh bagaimana orang menghabiskan waktu mereka (aktivitas), apa yang mereka anggap penting dalam lingkungannya (ketertarikan), dan apa yang mereka pikirkan tentang diri mereka sendiri dan juga dunia disekitarnya (pendapat) (Setiadi, 2003:148).

Gaya hidup lebih menggambarkan perilaku seseorang, yaitu bagaimana ia hidup, menggunakan uangnya, dan memanfaatkan waktu yang dimilikinya (Sumarwan, 2014). Gaya hidup seringkali digambarkan dengan kegiatan, minat, dan opini dari seseorang (activities, interests, dan opinions). Secara umum (R. 
Daga : 2021) mengartikan gaya hidup sebagai suatu dikenali dengan bagaimana orang menghabiskan waktunya (aktivitas), apa yang penting orang pertimbangkan pada lingkungan (minat), dan apa yang orang pikirkan tentang diri sendiri dan dunia di sekitar (opini).

\section{Literasi Keuangan}

Pengetahuan literasi keuangan yang baik akan membuat seseorang memiliki pengelolaan uang yang baik dan terencana. Menurut Yushita (2017:16) literasi keuangan adalah kemampuan yang mencakup untuk membedakan pilihan keuangan, membahas uang dan masalah keuangan tanpa ketidaknyamanan, merencanakan masa depan, dan menanggapi kompeten untuk peristiwa kehidupan yang mempengaruhi keputusan keuangan sehari-hari, termasuk peristiwa di ekonomi secara umum.

The Organizationn for Economic co-operation and Development (OECD, 2017) dalam Oktafikasari \& Mahmud (2017) menjelaskan bahwa literasi keuangan merupakan sebuah kombinasi antara kesadaran, pengetahuan, keteramilan, sikap dan perilaku yang diperlukan untuk membuat keputusan keuangan yang masuk akal dan akhirnya mencapai kesejahteraan individu. Pengetahuan keuangan dapat membantu individu berkembang pahami masalah keuangan yang memungkinkan mereka memproses informasi kelola uang dan berikan keputusan bijak tentang manajemen keuangan pribadi.

Masyarakat Indonesia khususnya mahasiswa masih perlu berbenah meningkatkan tingkat literasi keuangan. Menurut hasil Survei Keaksaraan dan Integrasi Nasional

Keuangan (SNLIK) yang dilakukan oleh Otoritas Jasa Keuangan pada tahun 2016. Ada $67,8 \%$ orang yang menggunakan produk dan layanan keuangan. Berdasarkan hasil survey Nasional Literasi dan Inklusi Keuangan (SNLIK) yang dilakukan Otoritas Jasa Keuangan tahun 2016, terdapat 67,8\% masyarakat yang menggunakan produk dan layaanan keuangan. Namun hanya 29,7 \%nya yang memiliki pengetahuan, ketrampilan, dan kepercayaan yang memadai mengenai produk dan layanan keuangan. Demikian juga untuk 
kalangan pelajar dan mahasiswa, dengan tingkat inklusi keuangan sebesar $64,2 \%$, tingkat literasi keuangan golongan ini masih rendah yakni sebesar $23,4 \%$. Berdasarkan sudut pandang di atas tentang pengetahuan keuangan, dapat disimpulkan bahwa pengetahuan keuangan adalah kemampuan dalam mengaplikasikan pengetahuan dan pemahaman tentang konsep yang digunakan di bidang keuanga untuk membuatlah pilihan finansial yang cerdas.

\section{Pengelolaan Keuangan}

Pengelolaan keuangan merupakan bagian dari kegiatan manajemen keuangan pribadi yang merupakan proses seorang individu memenuhi kebutuan hidup melalui kegiatan mengelola sumber keuangan secara tersusun dan sistematis. Sina (2012 : 172-173) menjelaskan bahwa pengalaman keuangan merupakan kemampuan membuat suatu pertimbangan atau melakukan investasi di masa depan. Dengan perencanaan dan pengelolaan investasi yang baik dan benar akan mencapai ketentraman dan kenyamanan dalam hidup (Yulianti \& Silvy, $2013: 60$ ).

Mental accounting theory merupakan deskripsi mengenai cara seseorang melakukan proses akuntansi yang hanya dapat dipelajari dengan melakukan pengamatan mengenai perilaku seseorang atau menyimpulkan kaidah-kaidah yang berlaku di masyarakat (Silaya \& Persulessy, 2017 : 59). Menurut Bodie, Kane dan Marcus (2008 : 388) prospect theory memodifikasi deskripsi analitik dari investor risk averse rasional yang ditemukan dalam teori keuangan standar. Dalam hal ini prospect theory berhubungan dengan sikap pengambilan keputusan seseorang yang tidak hanya berdasarkan pertimbangan rasional tetapi aspek emosional juga berpengaruh di dalamnya. Dalam kondisi ketidakpastian individu akan memutuskan berdasarkan pertimbangan untung dan rugi. Pembuatan keputusan dalam kondisi ketidakpastian ini disebut dengan prospect theory. Keputusan tersebut dapat berubah jika terpaksa harus merubahanya karena dalam prospect theory akan mempertimbangkan titik referensi dari segala sudut. 


\section{Model penelitian}

Penelitian ini menganalisis hubungan antara gaya hidup dan literasi keuangan terhadap pengelolaan keuangan. Metode Analisis yang digunakan adalah regresi linier berganda.

Kerangka Berpikir

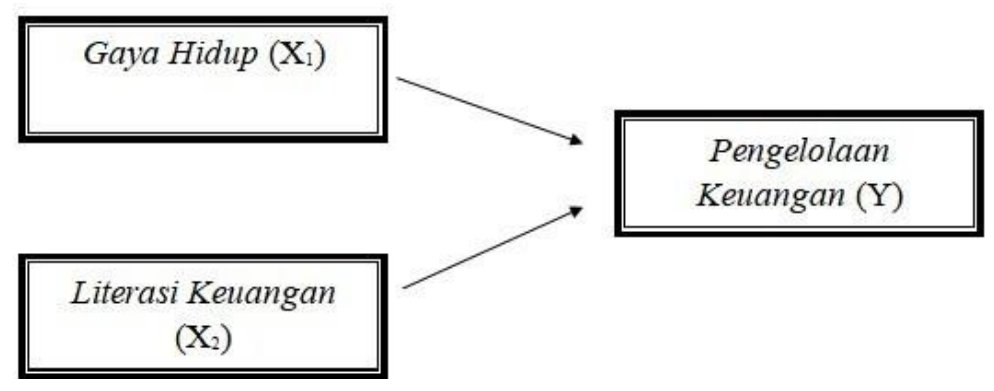

Gaya hidup dan literasi keuangan diteliti sebagai variabel independen dan pengelolaan keuangan diteliti sebagai variabel dependen.

\section{Metode penelitian}

\section{Prosedur pengambilan data}

Sumber data yang digunakan dalam penelitian ini adalah sumber data primer dengan metode pengumpulan data menggunakan kuesioner. Penelitian ini menggunakan model pengukuran skala likert. Menurut Syofian (2015:50) skala likert adalah skala yang dapat digunakan untuk mengukur sikap, pendapat dan persepsi seseorang tentang suatu objek atau fenomena tertentu.

Teknik analisis

\section{Uji validalitas}

Tujuan Melakukan Pengujian Validitas

Pengujian Vliditas dilakukan untuk mengetahui valid atau tidaknya instrument penelitian yang telah dibuat. Valid berarti instrumen tersebut dapat digunakan untuk mengukur apa yang seharusnya diukur. 
Rumus Statistik untuk Pengujian Validalitas

$$
\mathrm{r}_{\mathrm{xy}}=\frac{\mathrm{n} \sum_{\mathrm{i}=1}^{\mathrm{n}} \mathrm{x}_{\mathrm{i}} \mathrm{y}_{\mathrm{i}}-\sum_{\mathrm{i}=1}^{\mathrm{n}} \mathrm{x}_{\mathrm{i}} \sum_{\mathrm{i}=1}^{\mathrm{n}} \mathrm{y}_{\mathrm{i}}}{\sqrt{\left(\mathrm{n} \sum_{\mathrm{i}=1}^{\mathrm{n}} \mathrm{x}_{\mathrm{i}}^{2}-\left(\sum_{\mathrm{i}=1}^{\mathrm{n}} \mathrm{x}_{\mathrm{i}}\right)^{2}\right)\left(\mathrm{n} \sum_{\mathrm{i}=1}^{\mathrm{n}} \mathrm{y}_{\mathrm{i}}^{2}-\left(\sum_{\mathrm{i}=1}^{\mathrm{n}} \mathrm{y}_{\mathrm{i}}\right)^{2}\right)}}
$$

Dimana :

rxy $=$ Item instrumen variabel dengan totalnya $\mathrm{n}=$ Jumlah sample

$\sum x i=$ Jumlah pengamatan variabel $\mathrm{x}$

$\sum \mathrm{yi}=$ Jumlah pengamatan variabel $\mathrm{y}$

$\left(\sum \mathrm{xi}\right)=$ Jumlah kuadratPengamatan variabel $\mathrm{x}\left(\sum \mathrm{yi} 2\right)=$ Jumlah pengmatan variabel y

$(\Sigma \mathrm{xi}) 2=$ Kuadrat jumlah pengamatan variabel $\mathrm{x}\left(\sum \mathrm{yi}\right) 2=$ Pengamatan jumlah variabel y

$\sum$ xiyi $=$ Jumlah hasil kali variabel $\mathrm{x}$ dan $\mathrm{y}$

2.Uji realibilitas

Tujuan Melakukan Pengujian Reliabilitas

Pengujian Reliabilitas dilakukan untuk mengetahui sejauh mana suatu alat ukur dapat menghasilkan data yang reliable. Teknik yang dipakai untuk menguji reliabilitas pada penelitian ini menggunakan cronbach Alpha.

Rumus Statistik Pengujian Realibilitas

$$
r_{i}=\left(\frac{k}{k-1}\right)\left(1-\frac{\sum \sigma_{b}^{2}}{\sigma_{t}^{2}}\right)
$$

Dimana :

$r \quad=$ Reliabiltas instrument (cronbach alpha)

$\mathrm{k}=$ = Banyaknya butir pernyataan atau banyaknya soal

$\Sigma 2$ = Jumlah varians butir pernyataan

$\sigma \mathrm{t} 2=$ Varians total

Regresi Linear Berganda 
Regresi adalah suatu metode untuk menentukan sebab dan akibat antara satu variabel dengan variabel-variabel yang lain.

Secara umum rumus regresi berganda adalah sebagai berikut

$\mathrm{Y}=\mathrm{a}+\mathrm{b} 1 \mathrm{X} 1+\mathrm{b} 2 \mathrm{X} 2+\mathrm{e}$

Keterangan :

$\mathrm{Y}$ : Pengelolaan Keuangan

X1 : Gaya Hidup

X2 : Literasi Keuangan

a : Konstanta

$\beta 1$ dan $\beta 2$ : Koefisien regresi

\section{Uji Hipotesis}

a. Uji (Parsial)

Uji t digunakan untuk mengetahui apakah pengaruh masing- masing variabel bebas terhadap variabel terkait apakah bermakna atau tidak. Pengujian ini dilakukan dengan membandingkan antara nilai hitung masing-masing variabel bebas dengan nilai tabel dengan derajat kesalahan $5 \%$ dalam arti $(\alpha$ $=0.05$ ).

Jika signifikan $t>0,05$, maka variabel independen tidak berpengaruh terhadap variabel dependen

Jika signifikan $t<0,05$, maka variabel independen berpengaruh signifikan terhadap dependen 
b. Uji Simultan (Uji-F)

Menurut Ghozali (2012:97), uji simultan (uji-F) merupakan uji statistic yang menunjukkan apakah semua variabel independen yang dimasukkan ke dalam model memiliki pengaruh secarabersama-sama terhadap variabel dependen. 


\section{DAFTAR PUSTAKA}

Alfabeta. Anita Sari, Dian. (2015). Financial Literacy dan Perilaku Keuangan Mahasiswa. Jurnal Studi Kasus Mahasiswa STIE 'YPPI Rembang , 6 (1) : 171-174.

Azizah, N. S. (2020). Pengaruh literasi keuangan, gaya hidup pada perilaku keuangan pada generasi milenial. Prisma (Platform Riset Mahasiswa Akuntansi), 1(2), 92101. Bandung : PT Refika Aditma.

Daga, R. (2021). Pengaruh Lifestyle Dan Personality Terhadap Keputusan Nasabah Menggunakan Atm Bank Sulselbar Cabang Utama Makassar.

Dikria, O., \& Mintarti, S. U. (2016). Pengaruh Literasi Keuangan Dan Pengendalian Diri Terhadap Perilaku Konsumtif Mahasiswa Jurusan Ekonomi Pembangunan Fakultas Ekonomi Universitas Negeri Malang Angkatan 2013. Jurnal Pendidikan Ekonomi, 9(2), 128-139.

Kanserina, D., Haris, I. A., \& Nuridja, I. M. (2015). pengaruh literasi ekonomi dan gaya hidup terhadap perilaku konsumtif mahasiswa jurusan pendidikan ekonomi universitas pendidikan ganesha tahun 2015. Jurnal Pendidikan Ekonomi Undiksha, 5(1).

Pulungan, D. R., \& Febriaty, H. (2018). Pengaruh gaya hidup dan literasi keuangan terhadap perilaku konsumtif mahasiswa. Jurnal Riset Sains Manajemen, 2(3), 103110.

Putri, N. A., \& Lestari, D. (2019). Pengaruh Gaya Hidup dan Literasi Keuangan Terhadap Pengelolaan Keuangan Tenaga Kerja Muda di Jakarta. Akurasi: Jurnal Riset Akuntansi dan Keuangan, 1(1), 31-42.

Sugiyono (2012). Metode Kuantitatif Kualitatif dan R \& D Bandung; Alfabeta.

Sugiyono(2013)Metode Penelitian Kuantitatif dan R\&D Bandung

Sugiyono. (2016). Metode Penelitian Kuantitatif, Kualitatif dan R\&D. Bandung: Alfabeta.

Sunyoto, Danang. (2016) Metodologi Penelitian Akuntansi.

Widayati, Irin (2012). Faktor-faktor yang Mempengaruhi Literasi Finansial Mahasiswa Fakultas Ekonomi dan Bisnis Universitas Brawijaya. Jurnal dan Pendidikan 